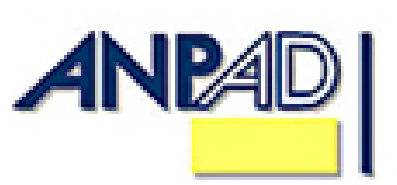

Disponível em

http://www.anpad.org.br/rac

RAC, Curitiba, v. 14, n. 4

pp. 752-760, Jul./Ago. 2010

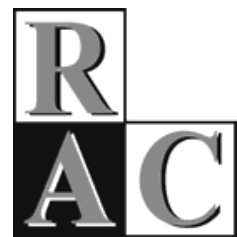

Documentos e Debates:

\title{
Tréplica - Riscos e Desafios do Pesquisador no País das Maravilhas: Reflexões sobre Trajetórias de Investigações em Alianças Estratégicas
}

\author{
Challenges and Pitfalls in Wonderland: Approaching Research Paths on Strategic \\ Alliances
}

Gláucia Maria Vasconcellos Vale *

Doutora em Administração pela UFLA.

Professora do PPGA da PUC Minas, Belo Horizonte/MG, Brasil.

Humberto Elias Garcia Lopes

Doutor pela UFMG.

Professor do PPGA da PUC Minas, Belo Horizonte/MG, Brasil.

* Endereço: Gláucia Maria Vasconcellos Vale

PUC Minas: Av. Itaú, 525, Dom Cabral, Belo Horizonte/MG, 30535-012. E-mails: galvale@terra.com.br; galvale@pq.cnpq.br

Copyright (C) 2010 RAC. Todos os direitos, inclusive de tradução, são reservados. É permitido citar parte de artigos sem autorização prévia desde que seja identificada a fonte. 
É gratificante e estimulante a iniciativa da RAC de promover o embate controversial entre pares, de longa tradição alhures, mas ainda modesto na nossa tradição acadêmica mais recente. A controvérsia assegura, em boa dose, o progresso do conhecimento. E mais atraente fica se, além da densidade e originalidade das contribuições e argumentações, é capaz de expor alguns dos traços elegantes que regem a arte da conversação. Salientamos, de inicio, que os autores Jorge Ferreira e Ângela da Rocha - que enfocam o problema da estrutura intelectual da produção científica na área - e Sandro Cabral e Sérgio G. Lazzarini - que abordam o tema da integração das perspectivas teóricas - contribuem, de maneira rica, para as reflexões em curso. Os comentários e pontos de vista por eles levantados, não os compartilhamos de todo. Ao refletirmos sobre nosso tema de interesse, lembramo-nos da sabedoria do gato Cheshire, quando diz para Alice: se você não sabe para onde quer ir, então qualquer caminho serve. A arte, assim como a ciência, ajuda a ampliar a nossa compreensão das coisas.

Ferreira e Rocha comentam que nosso trabalho contribuiu para a identificação de algumas teorias relevantes aplicadas à pesquisa sobre alianças estratégicas'. Mas consideram que seria ainda prematuro qualquer esforço de classificação na área, o que levaria, na visão deles, a abordagens impressionistas ou seja, de natureza mais subjetiva. Sugerem, em seu lugar, a utilização de métodos bibliométricos para mapeamento de cluster de autores influentes no campo de conhecimentos, como uma alternativa inicial mais realista, capaz de evitar, segundo eles, o caráter impressionístico das classificações. Embora a sugestão de utilização de bibliometria seja bem-vinda, acautelamo-nos quanto à proposição de sua prevalência sobre a alternativa por nós apresentada. Acreditamos que ambas são importantes e dotadas de utilidade. Ao mesmo tempo, atentamos para os riscos do parcialismo, como possibilidade presente na utilização do método bibliométrico. Por sua vez, Cabral e Lazzarini comentam que teríamos realizado um 'honesto levantamento bibliográfico' e que nosso trabalho de explicitação das teorias foi realizado com competência. Mas sugerem que o mapeamento das possibilidades teóricas, como o realizado, talvez não seja o mais importante. Para eles, 'a obtenção de boas respostas para boas perguntas passa pela capacidade de integração das diferentes teorias que permeiam o campo'. Nesse contexto, questionam nossas preocupações finais com a presença de maiores ou menores compatibilidades - ou incompatibilidades - teóricas presentes em diferentes abordagens e elaboram, a partir daí, sobre os riscos da fragmentação na ciência. Temos a louvar o mérito do esforço empreendido por estes dois últimos autores na defesa de certos argumentos, apesar de alguns reparos na seleção de citações bibliográficas. Mas, afora alguns de seus comentários de natureza mais geral - que nos pareceram, eventualmente, um pouco deslocados ou desfocados diretamente do tema em questão - não esposamos, exatamente, o mesmo ponto de vista. De qualquer forma, os argumentos levantados por cada um dos replicantes ensejam uma reflexão particular sobre trajetórias de investigações nesse rico campo de conhecimentos, em plena evolução.

\section{SOBRE CIÊNCIA, ClasSificaÇÕES E FragmentaÇão}

Ferreira e Rocha, ao comentarem três sistemas possíveis de classificação e suas propriedades comuns, sugerem que não seria possível enquadrar nosso trabalho em nenhum deles. Salienta-se, antes de mais nada, que mesmo nas ciências naturais, de onde deriva a preocupação com a classificação científica e onde esta foi aplicada, primeiramente, tal tema é considerado complexo e controvertido. Sem pretender avançar muito em tal assunto, lembramo-nos de introduzir algumas outras contribuições pertinentes à reflexão sobre classificações em ciências sociais e o nosso trabalho. Segundo Kaplan (1975) o objetivo da classificação é facilitar a consecução de um propósito qualquer e evidenciar as relações que devem ser levadas em consideração, sejam quais forem. Sua validade, nesse contexto, dependeria de seu propósito, do uso que lhe pretendemos atribuir. O problema da ciência é, então, de saber se o que foi conceituado se prestará ao uso pretendido. Segundo o autor, as classificações assinalam "as trilhas pelas quais podemos caminhar mais livremente no espaço lógico. Indicam as intersecções ou encruzilhadas na rede de relações” (1975, p. 55). 
Ao mesmo tempo, ao abordar o problema metodológico da delimitação - por ele descrito como o de selecionar o objeto último da investigação, o espaço-atributo de sua descrição e a estrutura conceitual onde é possível formular hipóteses a respeito - Kaplan afirma que (1975, p. 84) tal problema "só pode ser resolvido dentro do contexto da investigação e não com base nesta ou naquela premissa filosófica". Dessa maneira, segundo o autor, o cientista pode usar qualquer conceito que julgue útil, desde que suas observações sejam suscetíveis de verificação através da experiência ou, então, que tragam alguma contribuição para a ação. Entendemos que as contribuições que aportamos ao tema de interesse serão de utilidade para muitos pesquisadores. Permitem elucidar caminhos alternativos e sugerir algumas cautelas, ainda que, eventualmente, alguma perspectiva teórica possa não ter sido contemplada.

Khun (1982) observou que a evolução de muitas ciências ocorre a partir da fusão de partes de diferentes comunidades. Tal fenômeno, no ângulo de interesse de nosso trabalho, pode ser visto no caso do Paradigma Eclético da Produção Internacional, mencionado por Ferreira e Rocha, como uma das teorias ausentes de nossa classificação. Tal abordagem é utilizada, em particular, para análise de investimentos e movimentos de empresas multinacionais no cenário internacional. E vem, de fato, incorporando a temática das alianças estratégicas entre suas preocupações. E não poderia ser diferente, na medida em que considera que tais empresas se encontram insertas no contexto de uma economia de mercado, baseada em aliança, intensiva em conhecimentos e globalizada. Tal paradigma é um caso interessante de evolução e associação entre diferentes abordagens teóricas, como reconhece Dunning. Segundo ele (2000, p. 166), “o conteúdo e a capacidade de predição do paradigma eclético encontramse firmemente inseridos em diferentes teorias econômicas e de gestão". Citam-se, entre as de interesse do presente trabalho, as teorias da organização industrial e da visão baseada em recursos e proposições presentes na teoria dos custos de transação, já citadas entre as principais abordagens teóricas identificadas. Nesse contexto, além de ser uma abordagem derivada de outras, o paradigma eclético possui horizonte de aplicação muito particular. Indagamos até mesmo se seria de fato o caso de ser incluído entre as perspectivas teóricas básicas.

Associações e trocas entre diferentes áreas de conhecimentos representam fontes inesgotáveis de criação de novos conhecimentos, como demonstra o próprio exemplo acima. Mas nem sempre as comunicações fluem com facilidade entre os vários campos. Como já observado por Khun (1982), as disputas que envolvem diferentes escolas ou comunidades científicas (compostas por grupos maiores ou menores, mais gerais ou específicos), não são raras. Algumas destas comunidades abraçam os próprios paradigmas incompatíveis entre si. Certamente compartilhamos dos temores e receios manifestados por Cabral e Lazzarini sobre os riscos de fragmentações nas ciências, quaisquer que sejam suas causas. Mas questionamos a sugestão dos replicantes de que nossa preocupação com a presença de maiores ou menores incompatibilidades teóricas presentes entre distintas perspectivas teóricas possa concorrer para a fragmentação na área. Acreditamos que, longe de estimular a fragmentação, nosso trabalho, ao identificar algumas correntes teóricas possíveis e sugerir cautela na sua associação, poderá, sim, no nosso entendimento, evoluir e contribuir, ainda que modestamente, para pavimentar avanços no campo de conhecimentos.

Enquanto abordamos, no nosso artigo, os desafios e dificuldades encontrados no mapeamento de vasto corpo de conhecimentos, Cabral e Lazzarini elaboram as dores e as delícias de mapear um campo de conhecimentos. Falam até da importância de definir bem certas categorias analíticas, onde se incluem as unidades de análise. De fato, tal ponto é de fundamental importância. O estudo das organizações apresenta um grande conjunto de diferentes unidades de análise. Apenas para ficarmos restritos ao tema de interesse de nosso trabalho, para Simon (utilizado por Williamson), a unidade de análise é a premissa para a decisão. Na economia dos custos de transação é a transação. Na teoria das redes sociais, inspirada na sociologia econômica, são as instituições econômicas e a transação econômica. Os estudos de estratégia enfocam, com frequência, uma empresa ou, mais recentemente, também um grupo de empresas interligadas. Como salientado por Williamson (1998), definindo-se uma unidade de análise é fundamental verificar as dimensões críticas em que existem variações e, também, o problema focal em que a unidade de análise será aplicada. Para Williamson, por exemplo, no contexto da teoria dos custos de transação, as dimensões críticas seriam três (freqüência, incerteza e especificidade dos ativos) e o problema focal é a integração vertical. Ao mesmo tempo, os 
pressupostos que norteiam sua análise baseiam-se nos princípios de racionalidade limitada e comportamento calculista e interesseiro ou oportunístico. Para Granovetter as dimensões críticas seriam os laços e as relações e o problema focal residiria no processo de construção das instituições e transações. Seu pressuposto assenta-se na noção da importância das estruturas de relações sociais e da confiança na criação das instituições e transações.

\section{SObre Williamson e GranovetTer e os Dilemas nas CiênCIas SOCIAIS}

Cabral e Lazzarini parecem discordar da nossa afirmação de que algumas das teorias apresentam certas incompatibilidades entre si e dificilmente poderiam ser associadas em estudos empíricos. Em primeiro lugar, temos de comentar que dificuldades de associação não significam impossibilidades absolutas. Mas a tentativa de associação de teorias que apresentam, à primeira vista, certas incompatibilidades exige, já de saída, um profundo domínio dos dois campos de conhecimentos. Caso contrário, tal associação mostrar-se-á incoerente ou, na melhor das hipóteses, desnecessária. O que podemos verificar, mesmo em alguns trabalhos acadêmicos na área de estratégia, que associam duas ou mais proposições teóricas, é um relativo desconhecimento dos fundamentos básicos inerentes aos respectivos campos de conhecimentos abordados. Aí, de fato, qualquer caminho ou trajetória parece servir.

Para embasar seus argumentos, os replicantes utilizam, em particular, o caso da teoria dos custos de transação, de Williamson, contrapondo-a à teoria das redes sociais, fundamentada nos trabalhos de Granovetter. Salientam que, 'como a evolução posterior da literatura claramente demonstrou, considerações sobre o efeito das relações sociais não são incompatíveis com a abordagem dos custos de transação'. Os replicantes procuram embasar suas argumentações mencionando um texto de Williamson, de 1991, que, segundo eles, teria esclarecido os pontos de controvérsia então presentes entre Williamson e Granovetter. Segundo os autores da réplica, este artigo seria importante, pois Williamson teria aí admitido que "o efeito de confiança e relações sociais pode agir como um parâmetro de mudança: ou seja, algo que pode reduzir custos de transação e possibilitar ganhos de troca.” (Cabral \& Lazzarini, Réplica 1, p. 740). A este propósito e como exemplo, os autores da réplica mencionam, um trabalho mais recente nesse campo de interesse, elaborado por Gulati e Nickerson. Concluem, em seguida, o raciocínio geral, enfatizando o potencial de integração entre a economia organizacional e a sociologia econômica, citando Gibbons. Não compartilhamos, exatamente, do ponto de vista dos replicantes, nem imputamos a mesma importância que eles imputam a esta obra de Williamson, datada de 1991, no contexto do tema aqui enfocado. Salienta-se, antes de mais nada, que Williamson (1991), neste artigo em questão, enfoca o tema das organizações econômicas e não menciona Granovetter.

Vamos elaborar nossa resposta a Cabral e Lazzarini recorrendo a, ninguém menos, do que aos próprios autores mencionados, ou seja, a Granovetter e Williamson, que mantiveram interessante e fecundo diálogo ao longo dos anos. Como mencionado pelos autores da réplica, Granovetter (1985) elaborou, inicialmente, o seu argumento do embeddedness, contrapondo-o, a título de exemplo, aos pressupostos existentes na teoria dos custos de transação. Para ele, o que determina e condiciona as transações econômicas é a natureza das relações sociais e a confiança aí gerada e não, exatamente, a busca por redução nos custos de transação, esta fundamentada em pressupostos de comportamento interesseiro ou oportunístico. De fato, Williamson, posteriormente, vai referir-se aos argumentos de Granovetter, mas não exatamente no artigo de 1991. A resposta direta de Williamson a Granovetter veio depois, em 1992, quando o autor participa de um workshop na Universidade da Califórnia (Berkeley) e pode ser localizada particularmente em dois artigos (Williamson, 1994, 1998). Vamos recorrer ao artigo de 1998, onde este autor realiza uma reflexão sobre a evolução de sua teoria e suas interfaces com a sociologia econômica em geral, incluindo-a no pensamento do próprio Granovetter.

Para Williamson (1998), um dos pontos de tensão entre sua teoria e proposições presentes no contexto das teorias das organizações reside no tema da confiança. Williamson concorda com o 
argumento de Granovetter que elaborar comprometimentos confiáveis - através do uso de relações sociais, contrapartidas, regras transparentes de difusão de informações, mecanismos especializados de disputa, etc. - significa criar substitutos funcionais para a confiança. Salienta, no entanto, que "embora extremamente importantes para a organização econômica, tais substitutos não podem ser confundidos com (real) confiança” (Williamson, 1998, p. 56). Ao mesmo tempo, salienta que, devido ao fato de as relações comerciais serem invariavelmente calculistas, "o conceito de risco calculado (ao invés de confiança calculada) deve ser utilizado para descrever transações comerciais” (Williamson, 1998, p. 57). Subjacente a tal proposição existe o pressuposto do comportamento interesseiro (e não o da confiança, como pretendido por Granovetter). A preocupação em mitigar os efeitos do oportunismo possui um papel central na TCT, como reconhece o próprio Williamson. Por oportunismo Williamson (1998) refere-se à "busca do autointeresse com malicia” (p. 25). Muitos autores, ao enfocarem outros mecanismos específicos de coordenação de formas híbridas, a exemplo da confiança, das crenças, da liderança e da influência, procuram situar-se bem distantes do próprio Williamson (ver, por exemplo, Ménard, 2004). Para eles, neste ponto, em particular, residiria a grande incompatibilidade entre a visão de Williamson, baseados na busca do autointeresse com malícia e, por outro, proposições que se apoiam em outros pressupostos.

Mas, certamente, existem espaços de complementaridade entre as duas proposições teóricas. A começar pelo próprio objeto de análise, ou seja, as transações. Depois, existem elementos comuns entre, por um lado, o conceito de embeddedness, elaborado por Granovetter e, por outro, a preocupação de Williamson com o tema da governança, encadeado com o do ambiente institucional. O próprio Williamson (1998) reconhece a presença de complementaridades presentes no pensamento de ambos. Mas, visto em sua inteireza, o aparato teórico da teoria dos custos de transação, com sua preocupação com a governança, já teria, na visão de Williamson, incorporado a preocupação com o tema das instituições. Estas, utilizando um conceito de Douglass North, concebidas como um conjunto de regras e valores fundamentais no plano político, social e legal, que estabelecem as bases para a produção, a troca e a distribuição. Para Williamson, o ambiente institucional define os parâmetros. Mudanças nesse ambiente influenciariam as condições de governança e os custos de transação envolvidos. Ao mesmo tempo, ao enfocar, no contexto da TCT, uma preocupação com as formas híbridas, tal modelo já tornaria possível uma análise das redes e parcerias empresariais. Williamson até mesmo questiona a proposição de que a análise das redes possa ir além dos limites da própria teoria dos custos de transação.

Nesse ponto, vamos observar o texto de Gulati e Nickerson, mencionado pelos replicantes. Gulati e Nickerson (2008) analisam como a confiança interorganizacional influencia a escolha da governança e impacta o desempenho das relações de troca, em estudo que envolve 222 fornecedores de 2 empresas automobilísticas. Concluem que "o alto nível de confiança interorganizacional aumenta a probabilidade de que um modo de governança menos formal e de menor custo seja escolhido" (Gulati e Nickerson, 2008, p. 1). Observa-se que tais achados se encontram em sintonia com o aparato teórico compreendido pela teoria dos custos de transação, vista em sua inteireza. Dentro desta abordagem, pode-se considerar que alguns elementos então inseridos no contexto institucional - onde as empresas pesquisadas realizam suas atividades de produção e troca - alteram os custos relativos das transações, privilegiando certas formas híbridas de governança. Por outro lado, um pesquisador interessado em utilizar o aparato teórico de Granovetter, poderia tecer diferentes considerações, ao observar o mesmo fenômeno, ou seja, as relações entre as 222 empresas e as duas montadoras. Granovetter (1985) afirma que "nascidas de motivos puramente econômicos, relações econômicas repetitivas tornam-se, frequentemente, revestidas de conteúdo social, que enseja forte expectativa de confiança e ausência de oportunismo" (p. 61). O caso analisado permitiria constatar, no contexto do argumento geral sobre embeddedness, a veracidade de tal afirmação.

Certos construtos teóricos podem mostrar-se mais ou menos adequados à análise e compreensão de certos fenômenos organizacionais. Dependendo, entre outros fatores, da natureza do objeto a ser estudado, dos interesses do pesquisador, do contexto ou propósito da pesquisa, é possível lançar mão de uma ou de outra abordagem ou, evidentemente, de abordagens combinadas. Como já mencionamos no nosso texto original, a utilização concomitante de diferentes abordagens espelha uma tendência 
importante nos estudos correntes. Mas é necessário que as opções realizadas sejam dotadas de consistência lógica e coerência interna. Mesmo na ausência de incompatibilidades plenas, a associação entre diferentes teorias enseja, também, uma reflexão associada ao princípio da parcimônia, tão caro às ciências, em geral. Se, pelo menos a princípio, mais de uma abordagem teórica parece prestar-se à análise de um determinado fenômeno e, se cada uma delas, em sua inteireza, puder ser aplicada, de maneira independente, para a explicação deste mesmo fenômeno, restaria a indagação da utilidade do uso concomitante de ambas. A menos que exista um motivo particular, como no caso, por exemplo, de estudos comparativos interessados na aferição do grau de aplicabilidade prática de diferentes construtos teóricos, tema este já mencionado por nós, no texto original.

Cabral e Lazzarini procuram avançar em seus argumentos sobre as possibilidades de integração entre diferentes campos de conhecimento, citando um texto de Gibbons (2005), onde este autor elabora uma reflexão sobre as possibilidades de integração entre a sociologia econômica e a economia organizacional. Mas uma análise mais cuidadosa da literatura na área poderia mostrar que tal temática vem sendo, há mais tempo, explorada por outros autores. Incluem-se entre eles o próprio Williamson (1994, 1998). Ao mesmo tempo, inúmeros são os trabalhos que vêm explorando tais associações, no próprio contexto teórico ou teórico-empírico, a exemplo dos nossos (Vale, 2006, 2007; Vale, Amâncio, \& Wilkinson, 2008).

Podemos considerar que as reflexões de Williamson e Granovetter são, de certa forma, emblemáticas da presença de certa tensão, ainda hoje presente nas ciências sociais, problema este já mencionado por Williamson (1998). Granovetter também se refere a tal tema - mas de outra maneira, quando inicia a elaboração da concepção sobre embeddedness, distinguindo entre, por um lado, abordagens supersocializadas (excesso de preocupação com a dimensão social da ação econômica) e, por outro, abordagens subsocializadas (excesso de preocupação com as dimensões econômicas, em particular representadas pelas abordagens neoclássicas). Mas se Williamson - ainda que incorpore a preocupação com as instituições - enfatiza fundamentos da análise econômica na observação do fenômeno de interesse, Granovetter, por seu lado, destaca as raízes sociais dos fenômenos econômicos.

\section{SOBRE ALTERNATIVAS DE MAPEAMENTO DE UM CAMPO NASCENTE DE CONHECIMENTOS: REALISMO OU PARCIALISMO?}

Ferreira e Rocha consideram que o caráter ainda incipiente da disciplina em análise comprometeria, no momento, a utilização de sistemas de classificação. Em seu lugar, propõem a utilização de métodos bibliométricos, capazes, segundo eles, de mapear a estrutura intelectual da produção científica de alianças estratégicas, de maneira mais realista e menos impressionista ou seja, livre de visões subjetivas dos autores. A partir daí, em uma fase posterior, seria possível, na visão deles, a identificação de conjuntos de pensamentos prevalentes - combinação harmônica de teorias - e suas influências nas pesquisas. Os replicantes apresentam, como exemplo de levantamento bibliométrico, os resultados de uma pesquisa elaborada por Ramos-Rodrigues e Ruíz-Navarro na área de administração estratégica, baseada em uma análise de co-citação de autores. No contexto da bibliometria, a análise das citações permite a descrição de uma serie de padrões na produção do conhecimento científico. A partir daí seria possível identificar os autores mais citados ou mais produtivos, a elite de pesquisa, frentes de pesquisa, fator de impacto dos autores, procedência geográfica ou institucional dos autores, idade média da literatura, obsolescência, periódicos mais citados, conjunto de periódicos que compõem determinando campo do conhecimento, etc. (Araujo, 2006). A sugestão de se utilizar a bibliometria é bem-vinda no contexto atual. Poderá trazer contribuições interessantes. Mas nos acautelamos quanto à proposição de sua prevalência sobre outras estratégias de abordagens, em que se inclui a nossa, mesmo porque o método sugerido também possui suas limitações. 
Aliás, os próprios replicantes reconhecem a presença de alguns problemas. Referem-se, em especial, aos associados à seleção de documentos/autores considerados importantes, em detrimento de outros, sobretudo em contextos de seleção regional; à premissa de existência de certa proximidade conceitual ou metodológica dos trabalhos citados de maneira compartilhada; à subavaliação de produções mais recentes; à equivalência entre citação e relevância da publicação citada. Mas existem outros fatores, que também poderiam ser mencionados, a começar pela escolha da própria unidade ou categoria de análise e do corte a ser utilizado. Tal escolha, associada ao escopo de interesse da pesquisa, repercute, diretamente, nos resultados finais, dotando-os de maior ou menor abrangência ou de maior ou menor parcialidade. Incidem aí questões de natureza até mesmo mais operacional, tais como que periódicos pesquisar, que período de tempo incorporar, como incluir autores e obras mais recentes, como enfrentar eventual regionalização da produção científica etc. Ademais, como salienta Alvarenga (1998, p. 5), "a bibliometria considera como categorias livres de questionamento os autores e fontes autorizadas, como livros e periódicos”. Mas ao associá-la a proposições de Foucault sobre a arqueologia do saber, a autora levanta interessantes indagações e questionamentos sobre as formas prévias de continuidade que caracterizam uma unidade discursiva e que são aceitas sem qualquer problematização.

Araújo (2006), referindo-se à evolução mais recente da bibliometria, salienta que alguns pesquisadores passaram a questionar a validade dos estudos exclusivamente quantitativos, afirmando que a bibliometria "deveria passar a ser uma técnica de suporte a ser somada a outras na realização de estudos concretos” (p. 24). Recorre, nesse contexto, às próprias reflexões de Trzesniak (1998), sobre o que antecede à elaboração de indicadores quantitativos e às indagações de White, Wellman e Nazer (2004), se as citações refletem a estrutura social. Visando superar algumas das reconhecidas limitações, muitos trabalhos se vão utilizando de técnicas bibliométricas aliadas a outros referencias e métodos, sugestivos de contextos específicos, associados à natureza da produção do conhecimento científico. Observemos a área de nosso interesse. Como já comentado, o campo de estudos das parcerias e alianças empresariais se vem estruturando como campo interdisciplinar, dotado de contribuições provenientes de várias áreas de conhecimentos. Cada uma delas dotada de diferente léxico básico. Mesmo estudos bibliométricos capazes de processar palavras-chave teriam enormes dificuldades de superar problemas semânticos existentes entre as áreas.

Mas retornemos à pesquisa bibliométrica sobre administração estratégica, mencionada por Ferreira e Rocha. Os replicantes comentam que este trabalho envolveu 1.045 autores, 870 artigos, 41.674 referências a 21.696 diferentes trabalhos, publicados no Strategic Management Journal, no período 1980-2000. Na visão dos dois autores, o resultado 'do estudo empírico permitiu a identificação da estrutura intelectual da pesquisa em administração estratégica’. No nosso julgamento, os resultados encontrados, embora interessantes, permitiram identificar apenas alguns elementos desta estrutura intelectual. Ou seja, apresentam uma visão apenas parcial do conjunto. Isso porque, embora o periódico citado possa ser dos mais relevantes na área, não se pode dizer, a princípio, que seja representativo de todo um universo de interesses e produções nesse campo de conhecimentos. Ademais, observamos que tal pesquisa realizou um mapeamento de um campo de conhecimentos relativamente consolidado. O que fazer no mapeamento de um campo nascente de conhecimentos? Como captar a riqueza das contribuições provenientes de várias disciplinas, dispersas em diferentes lócus e dotadas, eventualmente, de léxicos diferentes? Indagamos, nesse contexto, se seria de fato possível ou conveniente prescindir de métodos julgados mais impressionísticos. Será que a utilização concomitante dos dois métodos não poderia, no estágio atual, trazer resultados mais efetivos?

\section{CONSIDERAÇÕES FINAIS}

Refletindo sobre os fundamentos de nosso diálogo, enfatizamos que compartilhamos das preocupações de Cabral e Lazzarini sobre os riscos de fragmentação nas ciências, quaisquer que sejam suas causas. Mas acreditamos que a explicitação de alternativas e possibilidades de análises terá 
repercussão positiva, no sentido de facilitar a integração, de maneira mais coerente, entre diferentes abordagens teóricas. Ao mesmo tempo, consideramos interessantes as sugestões de Ferreira e Rocha, para a utilização da bibliometria. Ponderamos, no entanto, que tal método - que também possui suas limitações - não necessita preceder à realização de um trabalho do tipo que realizamos. É possível usufruir das vantagens e utilidades de ambos os caminhos, conjuntamente. Como em toda nova fronteira de conhecimentos, ocorre-nos o debate entre Alice e Humpty Dumpty - personagens fictícios da obra prima de Charles Lutwidge Dogson, que assina como Lewis Carroll, "Through the LookingGlass and What Alice Found There" - em que Alice coloca: "o fulcro é se você pode fazer as palavras dizerem muitas coisas diferentes"; ao que Humpty Dumpty pondera "a questão é quem vai ser o mestre - isto é tudo".

\section{AGRADECIMENTOS}

Agradecimentos ao CNPQ, pelo aporte de recursos ao projeto sobre redes empresariais e estratégias colaborativas, sob a coordenação da Prof ${ }^{\mathrm{a}}$. Gláucia Maria Vasconcellos Vale.

\section{REFERÊNCIAS BIBLIOGRÁFICAS}

Alvarenga, L. (1998). Bibliometria e arqueologia de saber de Michel Foucault: traços de identidade teórico-metodológica. Ciência da Informação, http://www.scielo.br/pdf/ci/v27n3/27n3a02.pdf

Araujo, C. A. (2006). Bibliometria: evolução histórica e questões atuais. Em Questão, 12(1), 11-32.

Dunning, J. H. (2000). The eclectic paradigm as an envelope for economic and business theories of MNE activity. International Business Review, 9(2), 163-190.

Gibbons, R. (2005). What is economic sociology and should any economists care? Journal of Economic Perspectives, 19(1), 3-7.

Granovetter, M. (1985). Economic action and social structure: the problem of embeddedness. American Journal of Sociology, 91(3), 481-510.

Gulati, R., \& Nickerson, J. A. (2008). Interorganizational trust, governance choice, and exchange performance. Organization Science, 19(5), 688-708.

Kaplan, A. (1975). A conduta na pesquisa. São Paulo: Editora da Universidade de São Paulo.

Khun, T. S. (1982). A estrutura das revoluções científicas. São Paulo: Editora Perspectiva.

Ménard, C. (2004). The economics of hybrid organizations. Journal of Institutional and Theoretical Economics, 160(3), 1-32.

Trzesniak, P. (1998). Indicadores quantitativos: reflexões que antecedem seu estabelecimento. Ciência da Informação, 27(2), 159-164.

Vale, G. M. V. (2006). Laços como ativos territoriais: análise das aglomerações produtivas na perspectiva do capital social. Tese de doutorado, Universidade Federal de Lavras, Lavras, MG, Brasil.

Vale, G. M. V. (2007). Territórios vitoriosos: o papel das redes organizacionais. Rio de Janeiro: Garamond. 
Vale, G. M. V., Amâncio, R., \& Wilkinson, J. (2008). Empreendedorismo, inovação e redes: uma nova abordagem. RAE Eletrônica, 7(1), art. 7. http://www.scielo.br/pdf/raeel/v7n1/a08v7n1.pdf

White, H., Wellman, B., \& Nazer, N. (2004). Does citation reflect social structure? Journal of the American Society for Information Science and Technology, 55(2), 111-126.

Williamson, O. E. (1991). Comparative economic organization: the analysis of discrete structural alternatives. Administrative Science Quarterly, 36(2), 269-296.

Williamson, O. (1994). Transaction cost economics and organizational theory. In N. Smelser \& R. Swedberg (Eds.), Handbook of economic sociology (pp. 77-107). Princeton, NJ: Princeton University Press.

Williamson, O. (1998). Transaction cost economics and organizational theory. In G. Dosi, D. J. Teece, \& J. Chytry (Eds.), Technology, organization, and competitiveness: perspectives on industrial and corporate change (pp. 17-65). Oxford: Oxford University Press. 